Full Length Article

\title{
Building envelope systems for the circular economy; Evaluation parameters, current performance and key challenges
}

\author{
Gerard Finch *, Guy Marriage, Antony Pelosi, Morten Gjerde \\ Victoria University of Wellington, New Zealand
}

\section{A R T I C L E I N F O}

\section{Keywords:}

Circular economy

Circularity indicators

Built environment

Building industry

Recycling

Material reuse

\begin{abstract}
A B S T R A C T
The building industry is the world's largest consumer of raw materials. In an effort to reduce the rate of consumption there is an urgent need to adopt more efficient recycling and reuse practices in the building industry. Emerging to support this need is the circular economy framework (circularity) - a concept that aims to separate 'economic growth from environmental destruction'. Using the framework of circularity this research critically evaluates the 'reuse' performance of a key area of modern construction; the external envelope layers of timber framed buildings.

The research collates circular assessment criteria relevant to the evaluation of building envelope layers from literature. In conjunction with real-world deconstruction tests and the aforementioned circularity assessment criteria the study identifies two key trends limiting circularity in the building envelope; the widespread presence of fixings that irreversibly damage components, and the widespread use of chemically modified materials (i.e treated and/or engineered timber). Given the prevalence of such building methods in New Zealand, Australia and North America there is a clear need for research that proposes fixing and material technologies for building envelopes that meet circular economy design criteria.
\end{abstract}

\section{Introduction}

As we enter the third decade of the 21 st century the negative impacts that our society's buildings have on the natural environment are alarmingly apparent. In many countries we can trace almost half of all resource consumption back to the design, construction and upkeep of the built environment (Assefa \& Ambler, 2017). In the manufacturing of building materials, and in the operation of our buildings, we find more carbon dioxide emissions than in any other sector of the economy (Nuñez-Cacho, Górecki, Molina-Moreno, \& Corpas-Iglesias, 2018). We also see vast quantities of contaminated and low value waste materials being created as a consequence of buildings not being designed for the future. In some developed nations half of all waste is identified as being a product of the construction sector (Storey, Gjerde, Charleson, \& Pedersen, 2005). Collectively these issues suggest that we need to make urgent changes in the way our cities are designed and built.

Previous research published in the journal of Sustainable Cities and Society (SCS) has worked to identify theoretical frameworks and technical guidelines for the construction of buildings that address the aforementioned issues (Assefa \& Ambler, 2017; Attia, 2016;
Hildebrandt, Hagemann, \& Thrän, 2017; Paiho et al., 2020; Vardopoulos, 2019). Within these works there is an emerging trend that calls for buildings to better address embodied energy concerns by being designed to facilitate material recovery. Research published in SCS has dealt with these issues on a macro scale - looking at the sector holistically and working to identify the impact of alterative end-of-life approaches. Building on this work our research instead focuses on the Micro scale examining and addressing the issues of designing for a circular economy in a specific type of building. We examine the specific materials, design practices and code requirements of today's building systems through the lens of circularity and use this analysis to propose new, 'circular', building methods. Rather than assessing the impact this research seeks to identify how we might turn theory into practice.

\section{Background}

Buildings are not typically designed for recycling or value recovery. At the end of a building's useful life the most economically sensible way to manage materials today is to demolish the structure, undertake rudimentary sorting of materials and send the majority to landfill (EPA,

\footnotetext{
* Corresponding author at: Victoria University of Wellington, School of Architecture and Design, 139 Vivian Street, Te Aro, Wellington, 6011, New Zealand.

E-mail address: ged.finch@vuw.ac.nz (G. Finch).
} 
2016). Implications of these wasteful practices are visible in the ongoing environmental degradation caused by mining, material processing and landfilling at a rate that exceeds the natural carrying capacity of our planet (McDonough \& Braungart, 2009; Ajayi et al., 2015; Baker-Brown, 2017). Furthermore, today's methods for dealing with separated end-of-life building waste do not adequately address long term environmental issues. For example, countries like Australia, Singapore, the Netherlands and Japan report high levels of demolition material recycling, yet the majority of these materials are consistently down-cycled (Deloitte, 2015; Nakajima \& Russell, 2014; Schut, Crielaard, \& Mesman, 2015). The most common form of such material down-cycling is in concrete and masonry products (Akhtar \& Sarmah, 2018). Because the cement component of concrete is not recovered in any recycling process the demand for raw materials, particularly those of which are prone to producing large quantities of carbon dioxide (CO2), remains high (Morrison Hershfield Engineering; ATHENA Life Cycle Assessment). This down-cycling issue is common in many other building material waste management streams.

Consequently, there is a need for a superior way of managing materials at the end of their useful lives. The preeminent proposed approach to achieve this is adaptive reuse, and failing that, direct material reuse and high-value recycling, referred to in a theoretical context as a circular economy. The circular economy model (or circularity) has emerged from multiple schools of thought (see Winans, Kendall, \& Deng., 2017) and is much broader in ambition than mere material reuse and high-value recycling. The circular economy outlines an "industrial economy that is restorative by intention; aims to rely on renewable energy; minimises, tracks and eliminates the use of toxic chemicals; and eradicates waste through careful design" (Ellen MacArthur Foundation, 2013/2015). Most importantly, for the stewardship of building materials, within circularity is the concept of eliminating waste through careful design. Rather than relying on retrospective material recovery methods that often result in devalued materials (as we do today), circularity is a call for the pre-emptive designing-out of possible waste, toxic and low-value materials (Baker-Brown, 2017). Within the concept of circularity also lies high-level material 'reuse' strategies such as whole building reuse, or adaptive reuse, actions that are already commonplace today (Brand, 1994). Reuse and recovery of building components on different scales is covered in depth by Brand (1994) and Dijk, Tenpierik, and Dobbelsteen (2014). This study focuses specifically on the recovery of individual building layers in elements at the end of a buildings life.

Responding to the need for the immediate adoption of circular economy concepts in the built environment, this article sets out to identify specific technical barriers to the implementation of circularity in the external layers of buildings. These external layers include water and weather proofing, vapour control, air control and aspects of thermal control. A focus on such external layers of the building envelope was informed based on previous experiments carried out by the authors dealing with structural components (see Finch, 2019). To understand the potential circularity of the aforementioned layers, a comprehensive review of mainstream construction was undertaken using a variety of existing circular assessment methods. Technical drawing publications and physical deconstruction tests have been utilised as research tools to provide responses to the assessment frameworks. Evaluations of existing construction approaches help to improve the precision of circular assessment frameworks and lay the foundation for informed design proposals of circular construction methodologies.

\section{Circular evaluation parameters}

\subsection{Existing approaches}

To fully understand the conflicts between existing construction approaches and the circular economy, a breakdown of circular building principles is required. The difficulty is, however, that there remains no standardised way of evaluating or defining 'circular construction'
(Franklin-Johnson, Figge, \& Canning, 2016; Linder, Sarasini, \& Loon, 2017). Many frameworks have been established that outline best practices - representing generalised translations of circular concepts - but these often fail to inform specific design requirements. The lack of a single cohesive approach that covers specific technical requirements is thought to be a consequence of the "complexity of evaluating circular solutions" (Dijk et al., 2014). In principle, circularity should encompass every possible interaction and process related to a given material from material extraction through to decomposition (Ellen MacArthur Foundation, 2015). In the case of buildings, however, it is often not feasible to trace or predetermine material management (Storey et al., 2005). Materials in buildings typically remain deployed for such a long period of time that there is no guarantee materials will be able to be recovered, or worth recovering, at the end of the buildings useful life. Thus, it is difficult to devise a complete circular assessment and design process that treats all variables fairly. To this end, the research adopts and builds upon a limited selection of circular design assessments designed specifically for buildings. Through applying these selected theories and using them to both evaluate existing systems and to hypothesise new circular solutions, this research acts as a reality check for existing circular guidelines.

To form this refined selection of circular design evaluations appropriate for buildings, a literature review between June 2018 and January 2019 was undertaken. Using Google Scholar, JSTOR and ProQuest, articles were sourced that included any one of the following key phrases: 'circular economy assessment', 'circular economy indicator', 'circular economy product assessment', 'product circularity assessment methodology' and 'circularity indicator'. Results were then collated to identify specific circular assessment tools with the full list reported in Fig. 1. The publication, a 'Taxonomy of Circular Indicators' (written by Saidani, Yannou, Leroy, Cluzel, \& Kendall, 2019) significantly aided this circularity assessment tool search process. Saidani's work collated "55-sets of C-indicators developed by scholars, consulting companies and governmental agencies" (2019, p. 543). Combining this list with our own search resulted in the identification of 74 unique assessment tools (Fig. 1). This list of C-indicators (circularity indicators) was then sorted based on the scale in which the indicator was operating. For example, the 'Circular Economy Company Assessment Criteria (CECAC)' was deemed not to be directly relevant to accessing the circularity of a wall assembly as it operates on a company scale, rather than product level. Completing this sorting process required a complete simulated work-through of each 'C-indicator' in-order to fully determine its relevance to building systems. Saidani's work aided in this process as the collated indicators had already been somewhat sorted into the scales that they operated at. Saidani et al. referred to these levels as "macro (cities, regions), meso (business) or micro (products, components, materials)" (2019, p. 550). The relevant C-indicators are summarised below in Fig. 1. To further strengthen the selected set of circular building design criteria it was deemed appropriate to adopt other well cited circular assessment approaches for buildings that were not included within Sadani's taxonomy. Further notable inclusions were a white paper produced by a consortium of industry experts, including the Dutch Green Building Council and Metablic ${ }^{\circledR}$, titled A Framework for Circular Buildings (2016) (Kubbinga et al., 2018), Philip Crowther's work in the early 2000s relating to designing for deconstruction, and Minunno et al., 2018Minunno et al's work; Strategies for Applying the Circular Economy to Prefabricated Buildings (2017).

\subsection{Defining and categorising specific circularity indicators}

The curated circular indicator and guideline criteria were sorted into three categories relating to how they could be assessed. Categorisation was determined essential to streamline the process of carrying out a circular assessment. The assessment criteria were initially sorted into categories based on the complexity of potential answers. For example, if the response to an assessment question was yes or no, these questions 


\section{All Circularity Assessment Tools/Indicators}

Based on 'A taxonomy of circular Economy indicators' (Saidaniet al, 2019).

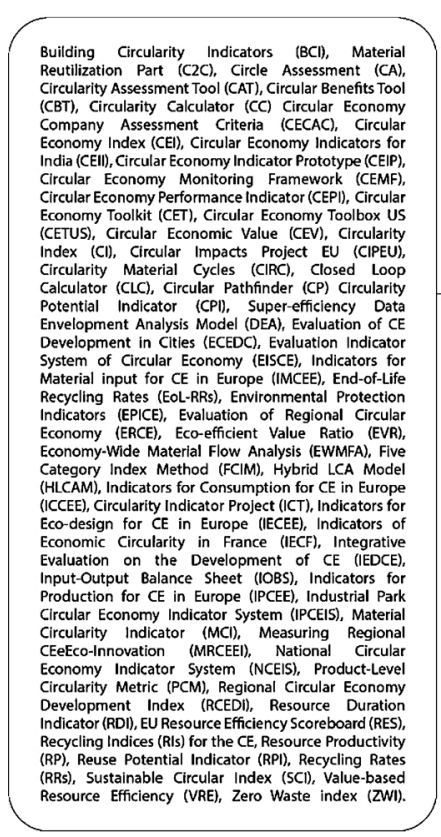

Product/Assembly Focused Assessments

With reference to (Walker et al, 2018 . Saidani et al, 2018/2019; EMF, 2015).

Building Circularity Indicator (BCI)

Circular Economy Indicator (CEIP) Circularity Calculator (CC)

Circular Economy Index (CEI)

Circular Economy Toolkit (CET)

Circularity Performance Indicator (CPI)

Closed Loop Calculator (CLC)

Eco-efficient Value Ratio (EVR) End-of-Life Recycling Rates (EoL-RRs) Input-Output Balance Sheet (IOBS)

Material Circularity Indicator (MCI) Product-Level Circularity Metric (PCM) Reuse Potential Indicator (RPI)

Resource Duration Indicator (RDI) Recycling Indices (RIs)
Circularity Measures Desirable for Assessing Buildings/Materials

Reference to (Crowther, 2005; DGBC and

Metablic, 2016; and Minunno et al; 2017).

Material Selection

Modularity

Flexibility

Adaptability

Upgradability

Functional Separation

Functional Independence

Clustering

Assembly Sequence

Interface Geometry

Type of Connection

Resale Value

Material Durability

Fig. 1. Sorting existing circularity indicators to arrive at approach appropriate for accessing building assemblies.

were grouped together. Consequently, three circular assessment categories emerged for 'product' level assessment of building envelopes; discrete, qualitative and measurable. Discrete characteristics defined criteria that were essentially true or false and that could be objectively validated. Discrete criteria typically referred to tangible, specific material qualities and fixing specifications. Qualitative characteristics were the opposite of this - criteria that were inherently subjective and needed to be carefully considered by a range of qualified stakeholders. Subjective criteria were centred on the presence or absence of features that would make material reuse attractive in the building material marketplace. They also included intangible design qualities such as using a 'standardised structural grid' - intangible because the definition (size and form) of a standardised grid varies significantly depending on construction materials and the buildings scale. Finally, measurable characteristics included criteria on a spectrum that could be, for the most part, objectively measured. Measurable characteristics included the quantity of waste or devalued materials produced after each use cycle and a record of the time involved to deconstruct a unit of wall. In the case of measurable assessment criteria typically a low value is best (unless otherwise noted).

The final criteria (listed above in Table 1) share major similarities with circularity assessment criteria not specific to the built environment or the envelope of timber framed buildings (see Saidani et al., 2019). This is seen as an ideal outcome as the principles of circularity are transferable regardless of the product under scrutiny, and a level of similarity suggests valid assessment criteria. However, to ensure that building envelope systems are appropriately evaluated the above table added further building specific details to each criteria. These details aimed to suggest how each criteria could be assessed/what factors should be looked for and are detailed in Section 3.1.

\section{Testing circularity indicators in the real world}

After consolidating the assessment criteria the research then acted to internally scrutinize these assessment criteria by undertaking real-world deconstruction of a building envelope assembly. Though this process the applicability of each assessment criteria could be determined based on the physical process of deconstruction and material recovery.

\subsection{New Zealand construction context}

The process of selecting an appropriate initial construction typology to evaluate was guided by local construction conditions. For reference purposes the following section briefly outlines the design of New Zealand's most common residential housing construction approach; platform timber framing.

As an evolution of light timber balloon framing, platform framing now dominates the New Zealand low and medium residential construction sectors (Isaacs, 2015). Characterised by its pink tinted boron treated pinus radiata structural members in standard dressed sizes (typically $90 \mathrm{~mm}$ or $140 \mathrm{~mm}$ by $45 \mathrm{~mm}-4$ " or 6" by 2") this type of framing is used in more than $90 \%$ of all new homes (Brunsdon \& Magan, 2018; Rosevear \& Curtis, 2015) (Fig. 2). The assembly typically consists of structural timber members orientated vertically (studs) at $450 \mathrm{~mm}$ or $600 \mathrm{~mm}$ spacing's, nailed to a bottom and top timber member of the same cross section (top and bottom plates) (Isaacs, 2015). Most New Zealand construction will also adopt regular blocking between studs at approximately $800 \mathrm{~mm}$ centres (Karunasena \& Leitch, 2009). Additionally, more than $80 \%$ of these structural frames arrive at construction sites preassembled (Brunsdon \& Magan, 2018). To provide structural resilience against earthquake and wind loads (lateral load resistance) sheet materials are then fixed to the frame members (Newcombe \& Batchelar, 2012). Fixings through the sheets are often at $150 \mathrm{~mm}$ centres (6") around the perimeter to provide adequate force transfer between sheet and vertical loadbearing structural timbers. The most common form of this sheet bracing in New Zealand is gypsum plasterboard internal wall linings (Brunsdon \& Magan, 2018). When additional bracing is required speciality gypsum wall lining products are available. In other countries utilising similar construction methods, lateral load resistance is achieved via external 'sarking' sheet products - such as orientated strand board, or plywood, fixed to the exterior of the buildings frame (Branco, Filipe, \& Lourenço, 2017). Structural sheet products and solid 
Table 1

Studies collated list of circular indicators and guidelines (based on literature reference in Fig. 1).

\begin{tabular}{|c|c|c|}
\hline $\begin{array}{l}\text { Discrete Design } \\
\text { Characteristics }\end{array}$ & $\begin{array}{l}\text { Qualitative Design } \\
\text { Characteristics }\end{array}$ & $\begin{array}{l}\text { Measurable Design } \\
\text { Characteristics (for } 1 \mathrm{~m}^{2} \\
\text { wall) }\end{array}$ \\
\hline $\begin{array}{l}\text { Use recycled and } \\
\text { recyclable materials. }\end{array}$ & $\begin{array}{l}\text { Use an open building } \\
\text { system (one that does not } \\
\text { require specialist } \\
\text { equipment or components } \\
\text { to use/reuse). }\end{array}$ & $\begin{array}{l}\text { The number of different } \\
\text { material types (lower is } \\
\text { better). }\end{array}$ \\
\hline $\begin{array}{l}\text { Make in-separable } \\
\text { subassemblies from the } \\
\text { same materials }\end{array}$ & $\begin{array}{l}\text { Provide end-of-life } \\
\text { identification of different } \\
\text { material types. }\end{array}$ & $\begin{array}{l}\text { The number of } \\
\text { connections (lower is } \\
\text { better). }\end{array}$ \\
\hline $\begin{array}{l}\text { Do not use secondary } \\
\text { finishes such as } \\
\text { chemical timber } \\
\text { preservatives. }\end{array}$ & $\begin{array}{l}\text { Make components sized to } \\
\text { suit the means of } \\
\text { handling. }\end{array}$ & $\begin{array}{l}\text { The numbers different } \\
\text { types of connections } \\
\text { (lower is better). }\end{array}$ \\
\hline $\begin{array}{l}\text { Do not use toxic and/or } \\
\text { hazardous materials. } \\
\text { Specifically Living } \\
\text { Building Challenge } \\
\text { red-List free only). }\end{array}$ & $\begin{array}{l}\text { Use modular design } \\
\text { (specifically a modular } \\
\text { spatial component that } \\
\text { allows solid elements to } \\
\text { be directly substituted by } \\
\text { transparent - window - } \\
\text { elements). }\end{array}$ & $\begin{array}{l}\text { The quantity of materials } \\
\text { with local high-value } \\
\text { recycling potential after } \\
\text { each use cycle (lower is } \\
\text { better). }\end{array}$ \\
\hline $\begin{array}{l}\text { Use mechanical not } \\
\text { chemical connections } \\
\text { between different } \\
\text { materials. }\end{array}$ & $\begin{array}{l}\text { Provide realistic } \\
\text { tolerances for assembly } \\
\text { and disassembly over } \\
\text { multiple use sequences } \\
\text { (between } 1 \text { and } 3 \mathrm{~mm} \\
\text { depending on materials). }\end{array}$ & $\begin{array}{l}\text { The quantity of fully } \\
\text { devalued (waste) } \\
\text { materials produced after } \\
\text { each use cycle (lower is } \\
\text { better). }\end{array}$ \\
\hline \multirow{2}{*}{$\begin{array}{l}\text { Separate the structure } \\
\text { from the cladding to } \\
\text { enable lifecycle based } \\
\text { material separation. }\end{array}$} & $\begin{array}{l}\text { Design to use common } \\
\text { tools and equipment. }\end{array}$ & \\
\hline & $\begin{array}{l}\text { Design joints and } \\
\text { components to withstand } \\
\text { repeated use (durability). } \\
\text { Use prefabrication and } \\
\text { standardisation. } \\
\text { Use light-weight materials } \\
\text { and components. }\end{array}$ & \\
\hline
\end{tabular}

timber members working together form the load bearing superstructure of almost all low and medium rise platform timber framed buildings in New Zealand.

To complete the external wall assembly in conventional construction; moisture, thermal and air control layers are added to the structural timber members. In most New Zealand buildings thermal control is achieved through the use of glass fibre insulation blankets fitted between the structural framing members (Brunsdon \& Magan, 2018). As glass fibre insulation blankets are semi-rigid they are self-supporting when orientated vertically and therefore only need to be friction fitted into the timber frames. On the outside face of the structure a moisture permeable synthetic building wrap is then fitted around the entire building (Law \& Dewsbury, 2018). The key role of this layer is to control air leakage and manage the air pressure differential between outside and inside. It is becoming more common in New Zealand, as building energy performance expectations rise, to replace this flexible building wrap with a rigid air barrier (RAB) (Overton, 2013). These are commonly either 7-9 mm treated plywood or 5-9 $\mathrm{mm}$ fibre cement sheeting with taped seams nailed to the timber frame. Recommended building practices then call for a $20 \mathrm{~mm}$ air gap between the air control layer (RAB or synthetic wrap) and the cladding materials (Künzel, Karagiozis, \& Kehrer., 2008). Commonly referred to as a 'ventilated cavity' this spacing acts to both reduce the air pressure differential and control moisture. The cavity is formed by nailing $20 \mathrm{~m}$ thick strips of vertically orientated treated timber or PVC onto wall studs - through the building wrap/RAB. Most buildings in New Zealand are then clad in either weatherboards (timber or fibre cement), or masonry (clay brick or stone) (again see Brunsdon \& Magan, 2018). Weatherboards are in most instances fixed to the frame with wire nails and painted to increase their durability and weather-tightness. Masonry claddings do not typically require cavity battens and utilise instead galvanised metal ties that are fixed to studs and embedded in concrete mortar between masonry modules. Note that due to the seismic risks in New Zealand masonry claddings are not designed to perform structurally. It is also important to note that external insulation systems and vapour control layers are not commonly adopted building practices in New Zealand timber framing.

\subsection{Data gathering methods}

Taking the curated list of circular design attributes, we can then systematically examine current construction - specifically platform timber framing in New Zealand (as per Section 2). The information to address the circularity criteria were mainly produced via physical full scale prototyping and deconstruction tests carried out by the author (Fig. 3). Multiple randomised sections of external wall measuring 400 $\mathrm{mm}$ by $400 \mathrm{~mm}$ by $120 \mathrm{~mm}$ were assembled and then disassembled under the guidance of deconstruction experts (Fig. 3). The process was video recorded, and all materials were systematically checked for damage and contaminants. A full stock take of materials was completed both before and after each test cycle. Additionally, the wall specifications (Section 2) could be used to answer some of the discrete circular criteria outright. Accompanying the physical deconstruction was another comprehensive review of literature published in this area reporting upon interviews with demolition experts. John Storey et al.'s 2005 A State of Deconstruction in New Zealand report was immensely valuable in this process as well as the more recent report on a whole house deconstruction project emerging from the 2011 Christchurch earthquake sequence (Zaman, Arnott, Mclntyre, \& Hannon, 2018). Collectively, this information enabled each circular criteria to be answered and recorded.

\subsection{Identified circular construction issues in New Zealand platform framing}

\section{(See Table 2).}

\section{Discussion}

\subsection{Contamination and material damage caused by fixings}

The most immediate circular weakness in the envelope of conventional construction is the widespread use of single use, damaging and often toxic, fixing solutions. The adhesives used behind wall sheathing, under floors and on the rear of internal wall linings are prone to causing damage on separation, and leave materials contaminated with adhesive residue (Finch, 2019). Deconstruction revealed that in most cases a single fixing punctured multiple envelope layers. For example, screw fixings are used in conjunction with adhesives through the same elements and are then often concealed under flashing tapes or plaster. These conditions further restrict high-value material recovery as they make locating fixings quickly almost impossible. Such circularity conflicts due to fixings can be expected throughout the United States of America, Canada and Australia due to very similar methods of construction in residential housing stocks (Isaacs, 2015). In fact, in climates cloder than New Zealand's, the issue of material recovery is likely to be even more complicated. A growing preference for spray foam insulation in the cavity of timer framing in the United States is a concern for circularity (Biswas, Shrestha, Bhandari, \& Desjarlais, 2016). Spray foam is designed to bond with all surfaces it comes in contact with to create an additional airtight barrier. Based on our own test, separation of this material is so time consuming that it is economic best practice to simply landfill the entire assembly. Fixings, adhesives, and inherently bonding materials (such as spray foam) are key weaknesses of conventional construction methods in respect to the circular economy. 


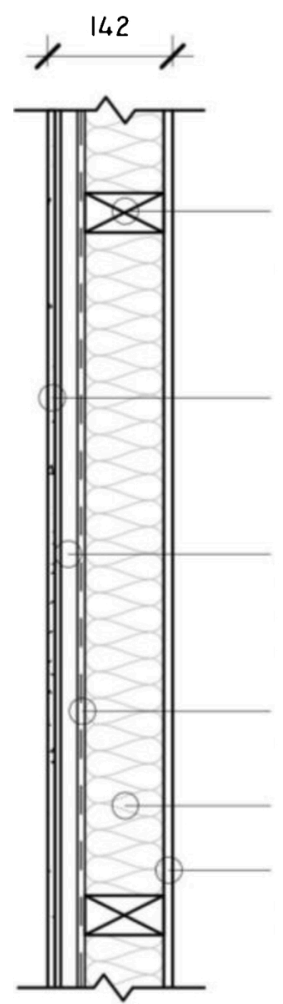

$90 \times 45 \mathrm{~mm} \mathrm{H1.2} \mathrm{structural} \mathrm{pinus} \mathrm{radiata}$ timber blocking at $800 \mathrm{~mm}$ centers fixed with two $90 \times 2.8 \mathrm{~mm}$ nails to each stud. $90 \times 45$ $\mathrm{mm} \mathrm{H1.2}$ structural pinus radiata timber studs at $600 \mathrm{~mm}$ centers.

$8 \mathrm{~mm}$ thick plaster over wire netting on $5 \mathrm{~mm}$ fibre cement sheet nailed to cavity battens with $60 \times 2.8 \mathrm{~mm}$ jolthead hot-dip galvanized nails at $300 \mathrm{~mm}$ centers.

$19 \times 45 \mathrm{~mm} \mathrm{H3.2}$ treated cavity batten nailed to structural frame with hand-driven $60 \times 2.8$ $\mathrm{mm}$ jolthead hot-dip galvanized nails at 300 mm centers.

Flexible wall underlay stapled to structural timber frame.

$90 \mathrm{~mm}$ thick fibre glass insulation batt.

$10 \mathrm{~mm}$ thick plasterboard fixed to studs and blocking with $25 \mathrm{~mm}$ screws and

plasterboard adhesive at $300 \mathrm{~mm}$ centers.

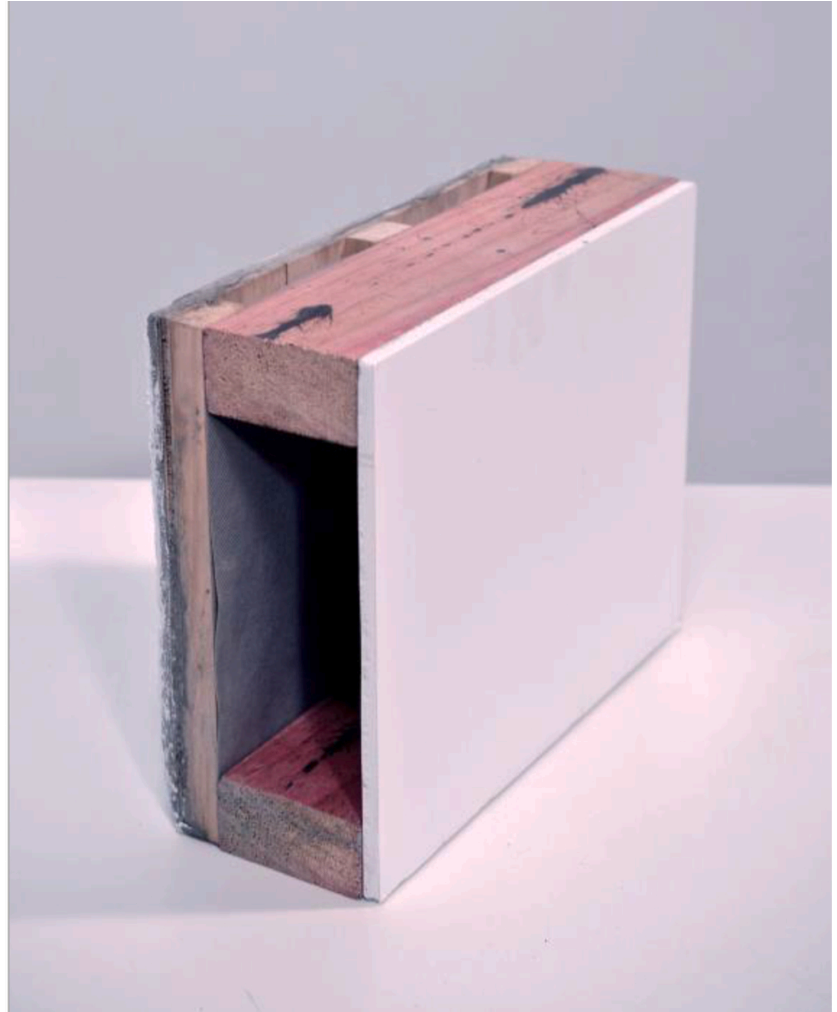

Fig. 2. Technical cross-section drawing of platform timber framing in New Zealand (left) and a built section of that framing (right).
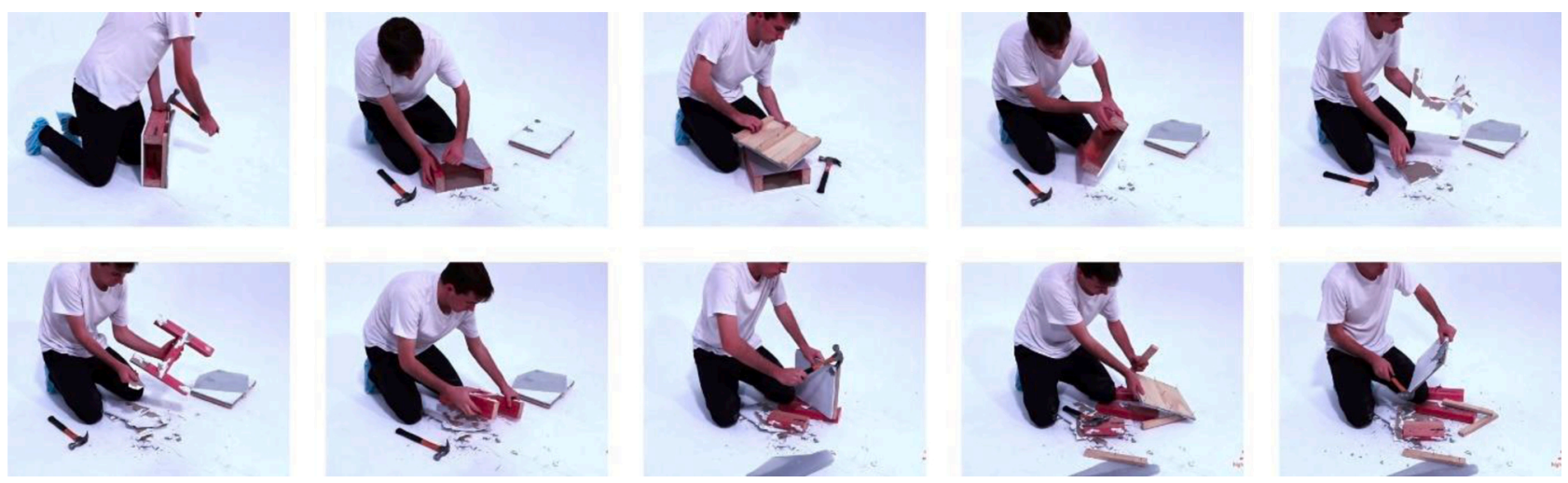

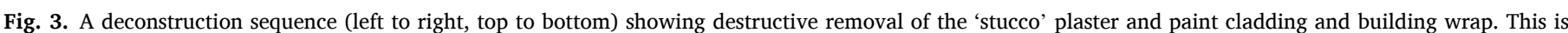

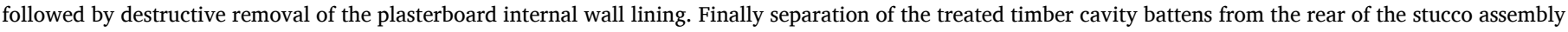
is attempted.

An additional barrier for material reuse in these structures appears to be a lack of standardised spatial geometries. With so many different shaped and sized construction materials coming from old buildings it is impossible to obtain large quantities of a consistent product (Nakajima \& Russell, 2014). Consequently, it becomes more economically sensible to purchase new materials (Storey et al., 2005). Compounding this problem is the fact that in New Zealand all windows are custom made to fix the specified opening. In most cases glazing specialists will come to site once the structure is erected and measure the openings. The result is a large 2nd hand window market in which almost no two windows are the same. Such variation in opening sizes has a flow on effect to an increased level of variation in the dimensions of lining materials. All theoretical circular assessment tools placed a major emphasis on ensuring as much standardisation as possible to maximise the reuse market (Saidani et al., 2019). It is therefore vital for material reuse and long-term sustainability that a higher level of standardisation is adopted into the construction sector.

\subsection{Implications of material chemical modification}

Concerns regarding the chemical composition of materials are also significant. As mentioned in section two, New Zealand requires by law that all Pinus Radiata structural framing timber is treated to level H1.2 (NZS3604:2011). The most common way to achieve this is with the spray on chemical agent Boron (NZS3602:2003). Once combined the preservative chemicals cannot be recovered without destroying the timber product (Forbes, 2018). Furthermore, the way the timber is required to be treated at the end of its useful life does not fit within a circular model. Boron can leach out of the timber and back into the ecosystem in an uncontrolled manner causing groundwater 
Table 2

Circular performance of external functional layers of New Zealand light timber platform framing (PF) (structure, waterproofing, thermal resistance, air and vapour control layers).

\section{Performance Criteria \\ Discrete Characteristics}

Recycled materials

High value recycling possible?

Secondary finishes on materials

Chemically hazardous materials

Chemical material connections

Reversible mechanical connections

Structurally independent layers

Qualitive Characteristics Use of an open buildings system

\section{Material types identified}

Components sized to suit the means of handling

Use of modular design

Provision for 'realistic' tolerances for assembly and disassembly

Disassembly requires only common tools and equipment

Joints and materials withstand repeated use (durability).

Adopt prefabrication

Use of lightweight materials

\footnotetext{
Measurable Characteristics (for $1 \mathrm{~m}^{2}$
} wall)

$$
\text { Circular Performance Notes }
$$

Platform framing does not typically use recycled materials however cavity battens in some instances can be made from recycled plastics. Cladding layers can also use recycled materials, but this is rare.

Some. Many materials become contaminated, however, HDPE polyethylene air barrier building wrap is recyclable, as is fibre glass and polyester insulation blankets.

Yes. Many secondary finishes - treated timber, in cavity and used in rigid air barriers (treated plywood).

Yes. Copper Chrome Arsenic (CCA) treated timber used in rigid airtightness layer. Yes. Interior plasterboard lining with acrylic paint adhesive fixed to timber frame. Tapes on airtightness layers. Few. Internal plasterboard linings used as vapor buffer is sometimes screwed to frame (but screw is plastered over).

No. Structural bracing for frame relies on external and internal sheet layers and thus imposes fixing conditions.

Platform framing is flexible in its ability to support a wide range of geometric and aesthetic possibilities, however it requires a high level of infrastructure to support this openness.

Generally there is no record on the deployed materials regarding chemical composition, life, or post use stewardship. It will be possible however for experts to identify specific materials.

This depends on how elements are categorised and separated. Most elements can be assembled and disassembled with only one or two people however it is common to install larger pre-nailed frames that must be lifted by mechanical means. Although the structural elements are largely standardised (2400 mm high 45 $\mathrm{mm}$ by $90 \mathrm{~mm}$ timbers) all wall sections are custom built depending on opening locations, wall heights and lengths. There is no industry wide modulation standard for wall lengths. Yet, this construction technique could be deployed on a module if so desired.

Not applicable. All elements are custom cut to fit their end use case. No inherent joints/ connections. No components designed for repeated assembly or usage.

Generally only a Claw hammer is required however sophisticated de-nailing tools required for commercial deconstruction (to make reuse economically viable). Not applicable. All joints are butted or lapped. Air-tightness replies on taping joints - inherently not reusable. Some elements are prefabricated - i.e. prenailed frames. And this level of prefabrication can extend to claddings however this is extremely uncommon. Typically materials are categorised as lightweight. Air-barrier plywood is light weight as is cavity battens. Cladding/rain protection often heavy (brick/stone).
Table 2 (continued)

\begin{tabular}{ll}
\hline Performance Criteria & Circular Performance Notes \\
\hline Quantity of different types of materials & $\begin{array}{l}\text { For functional layers and structure, 12 } \\
\text { materials, typically: paint, gypsum, } \\
\text { construction adhesive, steel nail, pine } \\
\text { timber, boron treatment, fibre glass, } \\
\text { polyethylene wrap, steel alloy staples, CCA } \\
\text { treatment, stainless steel nails, fibre } \\
\text { cement. }\end{array}$ \\
$\begin{array}{ll}\text { Functional layers only, 7 fixing types. Nail } \\
\text { fixing for weatherboard cladding, cavity } \\
\text { battens, and RAB - however all using } \\
\text { different sizes. Tape and staples for flexible } \\
\text { connectors } & \text { warp when used, tape for seams in RAB } \\
& \text { when used. Adhesive and screw for } \\
\text { plasterboard. }\end{array}$ \\
Per metre square of wall platform framing \\
with the aforementioned cladding system \\
has 22 fixings. \\
Average quantity as a percentage of \\
materials in the assembly is 42 \%.
\end{tabular}

contamination (Parisio, 2006). Likewise, plywood used to form the rigid air barrier typically has an even higher level of timber treatment and includes adhesives between timber veneers (NZS3602:2003). The negative impact of this treated plywood product is likely to be more damaging then boron treated framing timber (Parisio, 2006). Chemical leaching is less of an issue, however, if these components are to be directly reused in new buildings. Yet it remains unknown if reused timber components would require re-treating with preservatives for every reuse instance. Based on the Australian draft standard for recycled structural timber it is unlikely that further treatment would be required, however treatments typically have a specified effective lifespan and assuming that they will continue to work has major legal and risk implications that requires further investigation (Crews, Haywood, \& MacKenzie, 2008).

Treated and engineered timber products also present value-recovery challenges when the fabricated timber elements are no longer fit for purpose. Recovering the pressure applied preservative chemicals from the timber is not possible with current technology and the implications of using treated timber in waste-to-energy equipment is largely unknown (John \& Buchanan, 2013). The only current end-of-life options for all treated timber material in New Zealand today is either reuse in a non-structural capacity (often furniture) or disposal into landfills (John \& Buchanan, 2013). Alternatively, timber preservative technologies that rely on heat and steam rather than chemicals are emerging and essentially eliminate the need for chemical timber preservation (Ormondroyd, Spear, \& Curling, 2015). Fortunately, most other materials in the functional layers of conventional timber framed construction are not chemically modified. Of note is the glass-fibre insulation, which is a highly processed inert material that can be efficiently recycled in a high-value manner (Asdrubali, D'Alessandro, \& Schiavoni., 2015). It is unknown whether high-value recycling of this material takes place, however. Again, further research is needed in this area (especially in a New Zealand context), to determine how insulation products are currently handled at end-of-life.

\subsection{Alterative disassembly approaches}

This research focused on complete separation of building assemblies at end-of-life and the implications of such practices. Yet there are a range of different deconstruction approaches that may be more appropriate depending on the way a platform timber framed building has been detailed. For example, if platform framing has been achieved through the use of regularly sized panels then separation and reuse of whole panels could be more sensible. An example of panelised platform framing is the EasyBuild system (EasyBuild, 2019). Each panel is strictly 
$1.2 \mathrm{~m}$ wide and has a solid timber member at each long edge. This effectively adds a level of redundancy to each panel, allowing one to be removed without having any impact on adjoining panels (Finch, 2019). Thus, a drawback of using panel based systems designed for deconstruction is an increase in cost due to the aforementioned redundancy (i. e. more timber). There are also visual implications in the sense that the EasyBuild system requires a larger portal frame post between each panel that breaks the continuity of the internal wall surface. Furthermore, if modifications are required to a panel, such as adding windows, waste will be produced that is identical to that coming from conventional platform framing. Thus the final end-of-life status of materials remain unchanged.

\section{Responding to the issues}

The process of establishing product specific circularity assessment criteria and completing an evaluation of the status quo was designed to provide a knowledge base for designed circular solutions/designed responses. A range of initial responses are outlined in Defab: Architecture for a Circular Economy (Finch, 2019). This section reports upon previously unpublished experiments.

\subsection{Interpreting the platform framing circular analysis}

Findings from the analysis of platform framing and common envelope systems used with this framing indicated that fixing methodologies and material section are the two major barriers to enabling circularity (see Section 3). From a design standpoint fixings can be directly addressed as they are dependent on the modulation and arrangement of different building layers. Modifications to fixing systems can informed by industry literature associated with various different building products. For example, there are a range of different sized cavity batten options available, and each size has accompanying literature that outlines specific fixing requirements. It is also possible to simulate (using computational tools) custom fixing configurations, or physically build and test those same configurations. Circularity issues such as the legal requirement to treat structural timber products are, however, not directly addressable from a design standpoint as they require legislation changes. Yet such challenges can be overcome by selecting a material already on the market that meets circular requirements (such as the aforementioned thermally modified timber products in place of Boron or CCA pressure treated timber). Also influencing the design responses is the evaluation of different deconstruction options - such as the choice to deconstruct a building into sub-components (i.e. panels) or to carry out total material separation. Such issues are discussed from a design point of view in Brand (1994) and Crowther (2005).

\subsection{A circular timber framing proposal}

Using thermally modified timber lengths of $20 \mathrm{~mm}$ by $140 \mathrm{~mm}$ and computer numerically controlled (CNC) routing fabrication a panelised building approach, based on the technical functional requirements of platform timber framing, has been proposed (Fig. 4). These panels aimed to address circular concerns on multiple levels by offering both recovery and reuse of assembled panel units, and of the sub-components within each panel. The system integrates diagonal bracing into each module in order to eliminate the need to perimeter fix sheet products to the external side of the panel. Slender vertical members are used to reduce the redundancy costs typically associated with panel based construction. To overcome buckling concerns these slender members are regularly intercepted by perpendicular timber plates and diagonal bracing members. The system uses $100 \%$ polyester insulation blankets that are factory cut to fit within the triangulated frame cavities. Air ingress is controlled by a thermally spun bound synthetic building wrap that is fixed in place using a continuous wiggle wire tension seam. A solid thermally modified structural timber cavity batten measuring $45 \mathrm{~mm}$

Air Barrier

polypropylene building wrap)

Cavity Batten

(Thermally modified solid timber

batten bolted to frame)

Cladding (as selected by client)

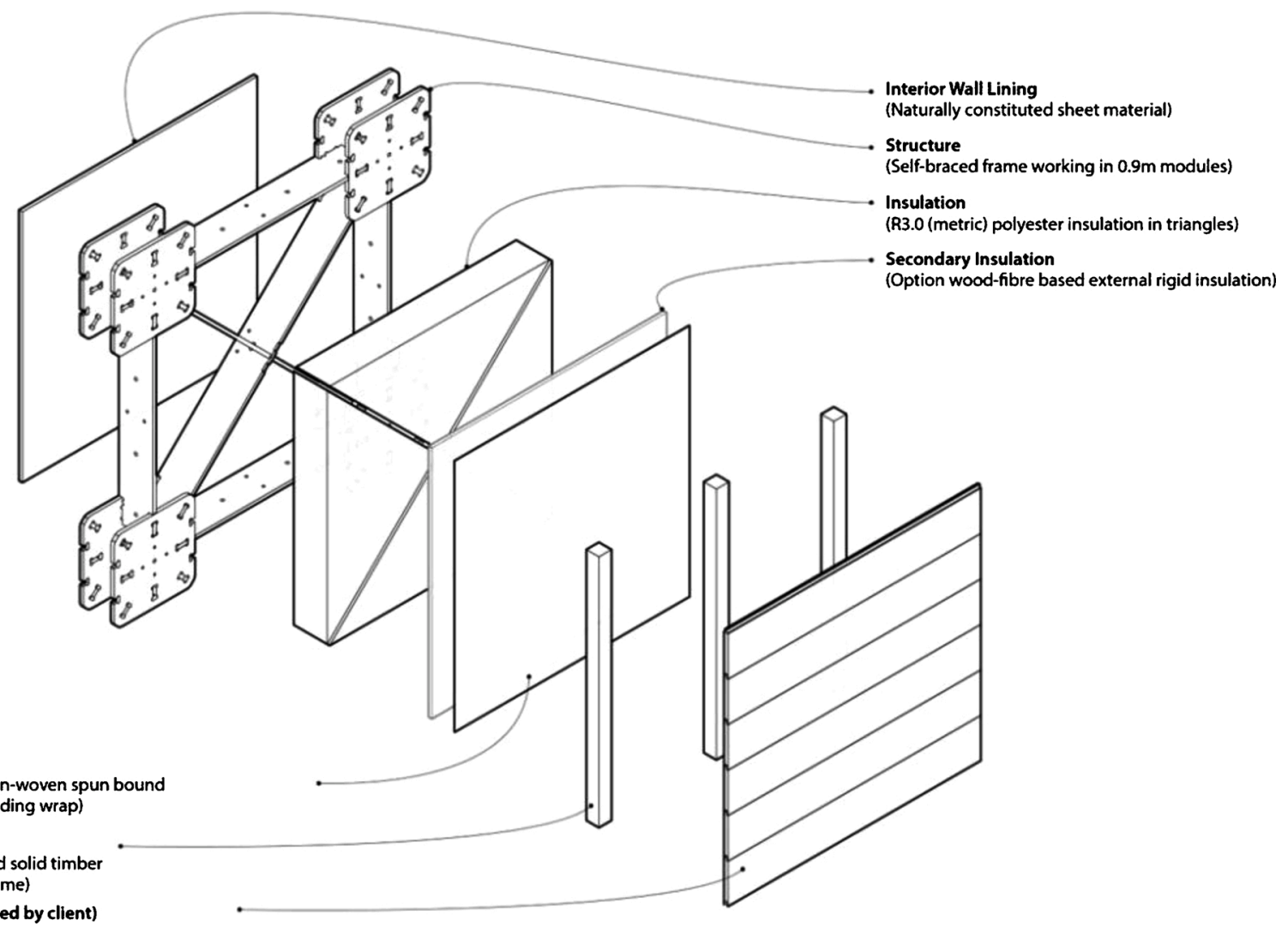

(Non-composite non-woven spun bound

Interior Wall Lining

(Self-braced frame working in $0.9 \mathrm{~m}$ modules)

Insulation

Secondary Insulation

(Option wood-fibre based external rigid insulation)

Fig. 4. Sketch of proposed circular wall envelope design (structure, waterproofing, thermal resistance, air and vapour control layers). 
square is then bolted into the main structural frame at regular intervals. This cavity batten has pre-seated insert nuts to allow the reversible fixing of various cladding products, including weatherboards, sheet metal or timber panels. The end result is a timber-centric circular economy based wall construction.

\subsection{Evaluations of proposed circular design}

The proposed circular construction system was evaluated under the criteria established in section one. Given the conceptual nature of this proposed system however no 'real-world' waste generation/durability data was collected. Working through the discrete evaluation criteria it became immediately clear that both the proposed building system and the evaluation framework needed further refinements. Within the proposed framework timber as a material proved difficult to categorise as although it cannot be recycled in a high-value manner, it can be directly reused, and is not inherently hazardous if disposed of in a responsible manner. The result was a material with circular benefits not being fairly represented in the evaluation. Thus, there is a need for the development of a circular assessment framework for buildings that can better categorise the circular performance of bio-based materials such as timber. The qualitative assessment criteria are difficult to respond to as they require informed speculative judgments. For example, we could consider the building system open in the sense that it is a conventional thickness and capable of working with mainstream building techniques. Yet a builder may argue that because the proposed system does not use conventional cavity battens (for example) it is a closed system. As such, for qualitative factors it appears that the most truthful assessment of circularity would be in the form of industry/public consultation. Furthermore, given the comparative basis of a circular assessment it would also be appropriate to move the 'light-weight materials' criteria from qualitative to measurable. Finally, results for the measurable performance criteria are easily produced, but do require a higher level of investment (i.e. the building and un-building of a sample unit), to provide accurate information (Table 3 ).

\section{Conclusion}

Following the theoretical framework of a circular economy this research established a curated set of evaluation criteria for the design of a circular building envelope. A multi-faceted criteria development process was adopted that examined both generic circular assessment approaches from literature, and those already optimised for use in the built environment. Twenty key circular performance criteria were identified and then sorted into three similar evaluative categories. To evaluate the validity of these criteria the research then used them to assess the circular potential of modern platform timber wall construction. The resulting evaluation indicated that all layers in the platform system assembly contradict circular design guidelines (as expected). Using the criteria, however, allowed the assessment to identify specific trends that prevent circularity. The first trend was identified as the widespread presence of fixing systems that irreversibly damage products. These include structural adhesives and nail fixings that penetrated multiple building layers. A second trend identified was the widespread presence of materials that have chemical alterations making them unable to be recycled in a meaningful way if direct reuse is not an option. The leading example of this was copper, chrome and arsenic (CCA) pressure treated timber, and engineered timber products (such as plywood). The third core concern related to the geometric qualities of formed components. Platform timber framing is an open system and thus can be constructed in a wide range of heights and lengths. Consequently, there is a lack of consistency in the size of external building layer materials, effectively reducing the likelihood of economical redeployment.

The results from this detailed circular analysis of the leading existing construction approach in New Zealand is alarming. For a country that prides itself in its natural environment and being an international leader
Table 3

Circular performance of external functional layers of proposed circular design (structure, waterproofing, thermal resistance, air and vapour control layers).

\begin{tabular}{|c|c|}
\hline Performance Criteria & Circular Performance Notes \\
\hline \multicolumn{2}{|l|}{ Discrete Characteristics } \\
\hline $\begin{array}{l}\text { Recycled materials and recyclable } \\
\text { materials. }\end{array}$ & $\begin{array}{l}\text { Timber }=\text { No. Building Wrap }=\text { Yes. Fixings } \\
=\text { Yes. Insulation = Yes. Cladding = Yes. }\end{array}$ \\
\hline High value recycling possible? & Yes. \\
\hline Secondary finishes on materials & No. \\
\hline Chemically hazardous materials & No. \\
\hline Chemical material connections & No. \\
\hline Reversible mechanical connections & Yes. \\
\hline Structurally independent layers & Yes. \\
\hline \multicolumn{2}{|l|}{ Qualitative Characteristics } \\
\hline Use of an open buildings system & See discussion in 4.3 \\
\hline Material types identified & $\begin{array}{l}\text { Some identifiable to specialist (thermally } \\
\text { modified timber) and some printed on } \\
\text { materials (insulation and building wrap). }\end{array}$ \\
\hline $\begin{array}{l}\text { Components sized to suit the means of } \\
\text { handling }\end{array}$ & $\begin{array}{l}\text { Assembled panels must be lifted in place } \\
\text { and out of place by at least } 2 \text { people. }\end{array}$ \\
\hline Use of modular design & $\begin{array}{l}\text { Modular based on a } 1.2 \mathrm{~m} \text { module, but } \\
\text { requires custom elements for no rectilinear } \\
\text { geometry. }\end{array}$ \\
\hline $\begin{array}{l}\text { Provision for 'realistic' tolerances for } \\
\text { assembly and disassembly }\end{array}$ & $\begin{array}{l}\text { Unknown - requires physical fabrication, } \\
\text { construction, deconstruction and } \\
\text { reconstruction. }\end{array}$ \\
\hline $\begin{array}{l}\text { Disassembly requires only common } \\
\text { tools and equipment }\end{array}$ & $\begin{array}{l}\text { An impact driver is required to fix bolts } \\
\text { quickly. This is common depending on the } \\
\text { builder. }\end{array}$ \\
\hline $\begin{array}{l}\text { Joints and materials withstand } \\
\text { repeated use (durability). }\end{array}$ & $\begin{array}{l}\text { Generally all fixings are reversible. The } \\
\text { long term durability of timber mortise and } \\
\text { tenon connections is unknown. }\end{array}$ \\
\hline Adopt prefabrication & $\begin{array}{l}\text { Level of prefabrication could vary } \\
\text { depending on cost and availability. } \\
\text { Prefabricated structural elements are } \\
\text { mixing with roll and bag products that are } \\
\text { not required to be fitted off-site. }\end{array}$ \\
\hline Use of lightweight materials & $\begin{array}{l}\text { Typically materials are categorised as } \\
\text { light-weight. Cladding/rain protection } \\
\text { could be heavy depending on client } \\
\text { selection. }\end{array}$ \\
\hline \multicolumn{2}{|l|}{$\begin{array}{l}\text { Measurable Characteristics (for } 1 \mathrm{~m}^{2} \\
\text { wall) }\end{array}$} \\
\hline Quantity of different types of materials & 4 \\
\hline $\begin{array}{l}\text { Quantity of different types of } \\
\text { connectors }\end{array}$ & 4 \\
\hline Quantity of Connectors & 8 \\
\hline $\begin{array}{l}\text { Quantity of devalued materials (waste) } \\
\text { after a use and deconstruction cycle }\end{array}$ & $\begin{array}{l}\text { Currently Untested - Requires physical } \\
\text { fabrication, assembly and disassembly. }\end{array}$ \\
\hline
\end{tabular}

in sustainable practices there remains the need for significant changes to the construction sector. The observations from the performance assessment are useful in bridging this gap as they provide a foundation for the design of effective circular building envelope solutions.

\section{Funding}

Funded by the Building Research Levy of New Zealand.

\section{Declaration of Competing Interest}

The authors report no declarations of interest.

\section{References}

Ajayi, Saheed O., et al. (2015). Waste effectiveness of the construction industry: Understanding the impediments and requisites for improvements. Resources Conservation and Recycling, 102, 101-112. https://doi.org/10.1016/j. resconrec. 2015.06.001. In press.

Akhtar, A., \& Sarmah, A. K. (2018). Construction and demolition waste generation and properties of recycled aggregate concrete: A global perspective. Journal of Cleaner Production, 186(June), 262-281. https://doi.org/10.1016/j.jclepro.2018.03.085

Asdrubali, F., D'Alessandro, F., \& Schiavoni, S. (2015). A review of unconventional sustainable building insulation materials. Sustainable Materials and Technologies, 4 (July), 1-17. https://doi.org/10.1016/j.susmat.2015.05.002 
Assefa, G., \& Ambler, C. (2017). To demolish or not to demolish: life cycle consideration of repurposing buildings. Sustainable Cities and Society, 28(January), 146-153. https://doi.org/10.1016/j.scs.2016.09.011

Attia, S. (2016). Towards regenerative and positive impact architecture: A comparison of two net zero energy buildings. Sustainable Cities and Society, 26(October), 393-406. https://doi.org/10.1016/j.scs.2016.04.017

Baker-Brown, D. (2017). The Re-Use atlas: A designer's guide towards a circular economy. RIBA Publishing.

Biswas, K., Shrestha, S. S., Bhandari, M. S., \& Desjarlais, A. O. (2016). Insulation materials for commercial buildings in North America: An assessment of lifetime energy and environmental impacts. Energy and Buildings, 112(January 2016), 256-269. https://doi.org/10.1016/j.enbuild.2015.12.013

Branco, J., Filipe, M., \& Lourenço, P. (2017). Experimental in-plane evaluation of light timber walls panels. Buildings, 7(4), 63. https://doi.org/10.3390/buildings7030063

Brand, S. (1994). How buildings learn: What happens after they're built. New York, United States of America: Viking Press.

Brunsdon, N., \& Magan, C. (2018). SR396 physical characteristics of new houses 2017. Study Report. Wellington: Building Research New Zealand.

Crews, K., Haywood, D., \& MacKenzie, C. (2008). Interim industry standard: Recycled timber - Visually stress graded recycled timber for structural purposes. Market knowledge \& development project number: PN06.1039. Forest \& Wood Products Australia.

Crowther, P. (2005). Design for disassembly - Themes and principles. RAIA/BDP environment design guide.

Deloitte. (2015). Screening template for construction and demolition waste management in the Netherlands (V2 - September 2015), 2. The Netherlands: Deloitte International.

Dijk, S., Tenpierik, M., \& Dobbelsteen, A. (2014). Continuing the building's cycles: A literature review and analysis of current systems theories in comparison with the theory of cradle to cradle. Resources, Conservation, and Recycling, 82(January), 21-34. https://doi.org/10.1016/j.resconrec.2013.10.007

EasyBuild. (2019). EasyBuild house packs. Masterton, New Zealand www.easybuild.co.nz.

Ellen MacArthur Foundation. (2013). Towards the circular economy; opportunities for the consumer goods sector. Ellen MacArthur Foundation. https://www.ellenmacarth urfoundation.org/assets/downloads/publications/TCE Report-2013.pdf.

Ellen MacArthur Foundation. (2015). Growth within: A circular economy vision for a competitive Europe. Ellen MacArthur Foundation.

EPA. (2016). Advancing sustainable materials management: 2014 fact sheet. United States of America: United States Environmental Protection Agency.

Finch, G. (2019). Defab: Architecture for a circular economy. New Zealand: Master of Architecture (Professional) Research Thesis. Victoria University of Wellington.

Forbes, N. (2018). Reusing Pinus Radiata Structurally in New Zealand. New Zealand: Master of Building Science Thesis. Victoria University of Wellington.

Franklin-Johnson, E., Figge, F., \& Canning, L. (2016). Resource duration as a managerial indicator for circular economy performance. Journal of Cleaner Production, 133 (October), 589-598. https://doi.org/10.1016/j.jclepro.2016.05.023

Hildebrandt, J., Hagemann, N., \& Thrän, D. (2017). The contribution of wood-based construction materials for leveraging a low carbon building sector in Europe. Sustainable Cities and Society, 34(October), 405-418. https://doi.org/10.1016/j. scs.2017.06.013

Isaacs, N. (2015). Making the New Zealand house 1792-1982. Wellington, New Zealand: Doctoral Dissertation, Victoria University of Wellington.

John, S., \& Buchanan, A. (2013). Review of end-of-life options for structural timber buildings in New Zealand and Australia.

Karunasena, W., \& Leitch, C. J. (2009). Investigation on role and function of noggings in residential timber frame construction, 7. Australia: Toowoomba.

Kubbinga, B., Bamberger, M., van Noort, E., van den Reek, D., Blok, M., Roemers, G., .. Faes, K. (2018). A framework for circular buildings: Indicators for possible inclusion in
BREEAM. Circle Economy SE, Dutch Green Building Council (DGBC), Metabolic, SGS Search and the Redevco Foundation.

Künzel, H. M., Karagiozis, A. N., \& Kehrer, M. (2008). Assessing the benefits of cavity ventilation by hygrothermal simulation, 4 .

Law, T., \& Dewsbury, M. (2018). The unintended consequence of building sustainably in Australia. Sustainable development research in the Asia-Pacific region.

Linder, M., Sarasini, S., \& Loon, P. (2017). A metric for quantifying product-level circularity: Product-level circularity metric. Journal of Industrial Ecology, 21(3), 545-558. https://doi.org/10.1111/jiec.12552

McDonough, William, \& Braungart, Michael (2009). Cradle to Cradle. Vintage.

Minunno, R., O'Grady, T., Morrison, G., Gruner, R., \& Colling, M. (2018). Strategies for applying the circular economy to prefabricated buildings. Buildings, 8(9), 125. https://doi.org/10.3390/buildings8090125

Barriers for deconstruction and Reuse/Recycling of construction materials. In Nakajima, S., \& Russell, M. (Eds.), Working commission W115 construction materials stewardship 397, (2014). International Council for Research and Innovation in Building and Construction (CIB).

Newcombe, M. P., \& Batchelar, M. L. (2012). Seismic design of plasterboard wall bracing systems. SESOC Journal, 25(2), 42-51.

Nuñez-Cacho, P., Górecki, J., Molina-Moreno, V., \& Corpas-Iglesias, F. (2018). What gets measured, gets done: Development of a circular economy measurement scale for building industry. Sustainability, 10(7), 2340. https://doi.org/10.3390/su10072340

NZS3602:2003. (2003). Timber and wood-based products for use in building. Wellington: New Zealand Standard. New Zealand Goverment.

Ormondroyd, G., Spear, M., \& Curling, S. (2015). Modified Wood: Review of efficacy and service life testing. In Proceedings of the Institution of Civil Engineers - Construction Materials, 168 pp. 187-203). https://doi.org/10.1680/coma.14.00072

Paiho, S., Mäki, E., Wessberg, N., Paavola, M., Tuominen, P., Antikainen, M., ... Jung, N. (2020). "Towards circular cities-Conceptualizing core aspects." ustainable cities and society. April, 102143. https://doi.org/10.1016/j.scs.2020.102143.

Parisio, S. (2006). Arsenic \& Old landfills: What we have learned from post-closure groundwater monitoring at inactive landfills in NY State. New York State department of environmental conservation. 2006 SBRP Workshop on Arsenic and Landfills: Protecting Water Quality. United States of America.

Rosevear, M., \& Curtis, M. (2015). Physical characteristics of New houses 2015. Study report. Physical characteristics of new houses. Wellington: Building Research New Zealand.

Saidani, M., Yannou, B., Leroy, Y., Cluzel, F., \& Kendall, A. (2019). A Taxonomy of Circular Economy Indicators. Journal of Cleaner Production, 207(January), 542-559. https://doi.org/10.1016/j.jclepro.2018.10.014

Schut, E., Crielaard, M., \& Mesman, M. (2015). Circular economy in the Dutch construction sector: A perspective for the market and government. Netherlands: National Institute for Public Health and the Environment.

Storey, J., Gjerde, M., Charleson, A., \& Pedersen, M. (2005). The State of deconstruction in New Zealand. In Deconstruction And materials reuse - An International overview, 93. Rotterdam (Netherlands): International Council for Research and Innovation in Building and Construction (CIB).

Vardopoulos, I. (2019). Critical sustainable development factors in the adaptive reuse of urban industrial buildings. A Fuzzy DEMATEL approach. Sustainable Cities and Society, 50(October), 101684. https://doi.org/10.1016/j.scs.2019.101684

Winans, K., Kendall, A., \& Deng, H. (2017). The history and current applications of the circular economy concept. Renewable and Sustainable Energy Reviews, 68(February), 825-833. https://doi.org/10.1016/j.rser.2016.09.123

Zaman, A., Arnott, J., Mclntyre, K., \& Hannon, J. (2018). Resource harvesting through a systematic deconstruction of the residential house: A case study of the "Whole house reuse" project in Christchurch, New Zealand. Sustainability, 10(10), 3430. https:// doi.org/10.3390/su10103430 (September 26. 